\title{
INTERPOLATION OF POSITIVE OPERATORS ON VARIABLE LEBESGUE SPACES
}

\author{
DAVID CRUZ-URIBE, SFO
}

Abstract. We prove an interpolation theorem for integral operators with positive kernel on the variable Lebesgue spaces. As an application we show that the set of exponents for spaces on which the Hardy-Littlewood maximal operator is bounded is convex.

Mathematics subject classification (2010): 42B20, 42B25.

Keywords and phrases: variable Lebesgue spaces, interpolation.

\section{REFERENCES}

[1] C. Bennett And R. Sharpley, Interpolation of operators, volume 129 of Pure and Applied Mathematics, Academic Press Inc., Boston, MA, 1988.

[2] D. Cruz-Uribe, L. Diening And A. Fiorenza, A new proof of the boundedness of maximal operators on variable Lebesgue spaces, Boll. Unione Mat. Ital. (9), 2(1): 151-173, 2009.

[3] A. DE LA TORRE, On the adjoint of the maximal function, In Function spaces, differential operators and nonlinear analysis (Paseky nad Jizerou, 1995), pages 189-194, Prometheus, Prague, 1996.

[4] L. Diening, Maximal function on Musielak-Orlicz spaces and generalized Lebesgue spaces, Bull. Sci. Math., 129(8): 657-700, 2005.

[5] L. Diening, P. Harjulehto, P. HÄstö And M. RŮŽIČKA, Lebesgue and Sobolev spaces with variable exponents, Springer, 2011.

[6] L. Diening, P. HÄstö AND A. NekVinda, Open problems in variable exponent Lebesgue and Sobolev spaces, In FSDONA04 Proceedings (Drabek and Rakosnik (eds.)); Milovy, Czech Republic, pages 38-58, Academy of Sciences of the Czech Republic, Prague, 2005.

[7] X. Fan And D. ZhaO, On the spaces $L^{p(x)}(\Omega)$ and $W^{m ; p(x)}(\Omega)$, J. Math. Anal. Appl., 263(2): 424 446, 2001.

[8] A. Yu. Karlovich AND A. K. Lerner, Commutators of singular integrals on generalized $L^{p}$ spaces with variable exponent, Publ. Mat., 49(1): 111-125, 2005.

[9] O. KovÁČIK AND J. RÁKosník, On spaces $L^{p(x)}$ and $W^{k ; p(x)}$, Czechoslovak Math. J., 41(116)(4): 592-618, 199.

[10] J. MusielaK, Orlicz spaces and modular spaces, volume 1034 of Lecture Notes in Mathematics, Springer-Verlag, Berlin, 1983.

[11] S. SAMKO, On a progress in the theory of Lebesgue spaces with variable exponent: maximal and singular operators, Integral Transforms Spec. Funct., 16(5-6): 461-482, 2005. 